Seminars in Perinatology supplement

Global maternal and child health: unfinished agenda

\title{
Implementation of the Every Newborn Action Plan: Progress and lessons learned
}

\section{Authors:}

Mary V. Kinney*, Olive Cocoman, Kim E. Dickson, Bernadette Daelmans, Nabila Zaka, Natasha R. Rhoda Sarah Moxon, Lily Kak, Joy E. Lawn, Neena Khadka, Gary L. Darmstadt

* Corresponding author

\section{Affiliations and email addresses for all authors}

Mary V. Kinney

Saving Newborn Lives, Save the Children

Mkinney@savechildren.org

Olive Cocoman

Every Newborn consultant

Geneva, Switzerland

cocomano@who.int

Dr. Kim Eva Dickson

Health Section, Programme Division

UNICEF HQ

kdickson@unicef.org

Dr. Bernadette Daelmans

Maternal, Child and Adolescent Health Department

WHO

daelmansb@who.int

Nabila Zaka

Health Section, Programme Division

UNICEF HQ

nzaka@unicef.org

Natasha Rhoda

Neonatal Care Improvement Advisor (Technical)- DFID|RMCH Project

Futures Group

Nrhoda@futuresgroup.com

Sarah G. Moxon, Maternal, Adolescent, Reproductive and Child Health (MARCH) Centre And Department of Infectious Disease Epidemiology, London School of Hygiene and Tropical Medicine sarah.moxon@Ishtm.ac.uk

Dr. Lily Kak

Office of Health, Infectious Diseases and Nutrition 
US Agency for International Development

LKak@usaid.gov

Prof. Joy E Lawn,

Maternal, Adolescent, Reproductive and Child Health (MARCH) Centre,

Department of Infectious Disease Epidemiology.

London School of Hygiene and Tropical Medicine, London

joy.lawn@Ishtm.ac.uk

Neena Khadka

Maternal Child Survival Programme/Save the Children

nkhadka@savechildren.org

Prof. Gary L. Darmstadt

Department of Pediatrics

Stanford University School of Medicine

gdarmstadt@gmail.com 


\begin{abstract}
Background

Progress in reducing newborn mortality has lagged behind progress in reducing maternal and child deaths. The Every Newborn Action Plan (ENAP) was launched in 2014 with the aim of achieving equitable and high-quality coverage of care for all women and newborns through links with other global and national plans and measurement and accountability frameworks. This paper aims to assess country progress and the supporting mechanisms in place to support country implementation of ENAP.
\end{abstract}

\title{
Methods
}

A country tracking tool was developed and piloted in October-December 2014 to collect data on ENAPrelated national milestones and implementation barriers in 18 high-burden countries. Simultaneously, a mapping exercise involving 47 semi-structured interviews with partner organisations was carried out to frame the categories of technical support available in countries to support care at and around the time of birth by health system building blocks. Existing literature and reports were assessed to further supplement analysis of country progress.

\section{Results}

Fifteen out of 18 high-burden countries have taken concrete actions to advance newborn health; four have developed specific action plans with an additional six in process and a further three strengthening newborn components within existing plans. Eight high-burden countries have a newborn mortality target, but only three have a stillbirth target. ENAP implementation in countries is well-supported by UN agencies, particularly UNICEF and WHO, as well as multilateral and bilateral agencies, especially in health workforce training. New financial commitments from development partners and private sector are substantial but tracking of national funding remains a challenge. For interventions with strong evidence, slow coverage persists and health information systems require investment and support to improve quality and quantity of data to guide and track progress.

\section{Conclusions}

Collaboration, appropriate technical support and innovation have been established to support some of the highest burden countries to establish newborn health action plans and facilitate the scale-up of evidence based interventions. Further progress will only be made with attention to context-specific implementation challenges, especially in areas that have been neglected to date such as quality improvement, sustained investment in training and monitoring health worker skills, support to budgeting and health financing, and strengthening of health information systems.

\section{Keywords}

Newborn, maternal, stillborn, implementation, mortality, survival, targets, bottlenecks, indicators 


\section{Background}

The world is currently reducing under-five and maternal deaths faster than at any time in history; 6.4 million fewer children died in 2013 compared to 1990, and maternal deaths have been cut by half. ${ }^{1}$ In the final year of the Millennium Development Goals (MDGs), the global community has been reviewing progress, reassessing development goals and aiming for a 'grand convergence' of life expectancy and health outcomes across the world. ${ }^{2}$ Ending preventable maternal and child deaths remains at the heart of this ambition with the Sustainable Development Goals maintaining specific targets for maternal, newborn and child survival. Countries have recognized that reaching goals requires targeted investments towards issue areas that have received the least attention and therefore experienced the least progress.

Due to less attention and investments, newborn deaths now account for at least $44 \%$ of all deaths among children under age five globally, and total 2.8 million deaths annually. ${ }^{3}$ From 1990 to 2013, the progress in reducing maternal mortality (3.5\% reduction per year) and under-five mortality after the neonatal period (3.6\% reduction per year) outpaced reductions in newborn mortality (2.2\% reduction per year). ${ }^{3-5}$ To this burden must be added stagnant reductions of the 2.6 million babies who die in the last 3 months of pregnancy or during childbirth (stillbirths). ${ }^{6}$ The knowledge and tools exists to prevent at least two thirds of newborn deaths and a third of stillbirths. ${ }^{7}$ Acting effectively on that knowledge, rapid progress is possible, especially when applying a systematic strategy that addresses the major causes of mortality and appropriately links key interventions across the postnatal period, underlining the inherent connections between reproductive, maternal, newborn, child and adolescent health (including nutrition) (RMNCAH). The Lancet Every Newborn Series published in 2014 demonstrated that the 'grand convergence' can only happen with much more investment in newborn health, which is the largest group of preventable mortality in under-five children ${ }^{8}$ with complications of prematurity now the leading cause of under-five child deaths globally. ${ }^{9}$

Many countries have made substantial progress towards reducing high newborn mortality with deliberate actions for newborn survival, for example in Bangladesh, Nepal, India, Pakistan, Malawi, and Uganda. ${ }^{4,8,10}$ Recognizing the rising proportion of newborns in their under-five child deaths, other countries wanted to learn from their success and sought guidance from partners. ${ }^{4}$ To support countries in their efforts to reduce newborn mortality, a group of over 60 partners, including academic institutions, health professional associations, multi-lateral and bilateral agencies, foundations, the private sector and civil society, including women's and parents' organizations, led by UNICEF and WHO, together with countries developed a global action plan for ending preventable newborn deaths and stillbirths. Based on evidence in The Lancet Every Newborn Series and wide consultation with countries and multiple organizations and individuals, the Every Newborn Action Plan (ENAP) presents maternal and newborn mortality and stillbirth targets to 2030 and 2035 and specific milestones at global and country level to 2020 (Panel 1). ${ }^{11}$ This action plan was discussed and endorsed at the World Health Assembly (WHA) in 2014 and supported by WHA Resolution WHA67.10. ${ }^{12}$ It officially launched on 30th June 2014, and countries have led the way in spearheading efforts to address maternal and newborn mortality and stillbirth prevention.

In order to achieve the national milestones and goals in ENAP, strong coordination and implementation is needed at all levels, most importantly in countries with the greatest burden of maternal and newborn mortality. Darmstadt and colleagues noted that "the key to progress in increasing coverage of interventions and saving newborn lives lies with and within countries". ${ }^{4}$ Putting policy into practice or scaling up newborn health interventions nationally requires country leadership, health system resources including workforce and funding, and technical capacity. Dickson and colleagues found that the most 
common gaps and barriers to country implementation of the highest impact interventions around the time of birth and for small and sick newborns include health financing and human resources. ${ }^{13-15}$ Lack of coordination among partners in providing technical assistance to countries was also noted. ${ }^{4}$

To advance the goals of ENAP at national and subnational levels, WHO and UNICEF coordinated four cross-cutting priority streams of activities: Advocacy, Country Implementation, Metrics, and Research. ${ }^{16}$ This structure aims to support countries in achieving the goals, targets and milestones of ENAP (Panel 1). In the past year, there has been much knowledge gained on how to strengthen technical support coordination as well as strengthen monitoring of country implementation and track progress. Likewise there have been impressive developments globally and in countries moving policies into the field for testing and scale up. The aim of this paper is to better understand how this unfinished agenda for women's and children's health is being supported in countries through this process and to identify lessons learned in how this support is translated into the actual scaling up of newborn health interventions, leading to accelerated reductions in mortality.

The objectives of this paper are:

1) To assess country progress in achieving the ENAP milestones

2) To identify what mechanisms are in place to support country implementation, including financial mobilization for newborn health

3) To identify newborn health-related interventions being taken to scale, and efforts to measure progress

\section{Methods}

To support national tracking of progress toward the achievement of ENAP goals, targets and milestones, a country tracking tool was developed and piloted to assess the status of progress towards ENAP milestones, identify barriers to implementation and map the specific technical assistance needs in each country. Tool design took place in August-October 2014. The tool was shared in October 2014 with 20 focus countries, selected based on the high burden of newborn mortality (deaths and rates). Data collection in countries took place from October to December 2014. The data collection process was supported by an "Every Newborn facilitating partner", who populated the tool with inputs from the newborn focal point at the Ministry of Health $(\mathrm{MOH})$, if available. The relevant $\mathrm{MOH}$ officials and key partners in the national Technical Working Group then reviewed and discussed responses. Due to the limited number of responses, a second, simplified exercise was undertaken by UNICEF to identify progress in the 18 countries with the highest burden of newborn deaths (deaths and rates) in terms of national newborn action plans and inclusion of the ENAP targets in their health plans. More details on these tools are available in Webannex A.

Simultaneously, a mapping exercise was undertaken to create a repository of the technical support to countries currently available for delivery of quality maternal and newborn care at the time around birth, including where the activity is taking place and what capacities and resources, both human and financial, available. The questionnaire design and draft repository development took place between SeptemberNovember 2014. The draft repository frames the categories of technical support using the WHO health systems building blocks. Semi-structured interviews began in October 2014 with partner organizations. Through a snowball approach, further partners were identified and in total 47 semi-structured interviews were undertaken with core partners. The information collected was reviewed and supplemented by the WHO country offices to ensure validity. 
A review of existing literature was conducted to identify key interventions and approaches poised for scale up. For countries identified as having made significant progress in their implementation strategies, further investigation to consider factors contributing to their success in scale up was undertaken. ${ }^{16}$

\section{Results}

\section{Country progress}

The WHA67.10 resolution urges Member States to put into practice the ENAP and requests periodic monitoring and reporting on progress to the WHA. ${ }^{12}$ Since the launch of the plan, many countries have taken action in response, and development partners have worked together to support government leadership, policymakers and program managers in implementing the actions laid out in the plan. Focussing specifically on the 18 countries which represent the top ten highest numbers of newborn deaths and/or the highest neonatal mortality rates, it was found that 15 have taken concrete actions to advance newborn health (Table 1). Four countries have developed specific action plans (Bangladesh, India, Indonesia and Kenya) and another six countries are in the process of preparing specific action plans (China, Guinea Bissau, Nigeria, Pakistan, Sierra Leone and Zimbabwe). An additional three countries have strengthened newborn components within existing plans for RMNCAH (Chad, Democratic Republic of Congo and Mali) and this work is also in progress in Ethiopia and Lesotho. Angola, The Central African Republic and Somalia have not yet started the development of plans and will need more support. While eight countries have a newborn mortality target, only three countries have a stillbirth target. A number of other countries not in the top 18 highest burden countries but with significant burdens of neonatal mortality have also embarked on the process of development of national newborn action plans or have revised existing strategies and plans and are implementing these plans including Afghanistan, Cameroon, Ghana, Malawi, Myanmar, the Philippines and Tanzania. ${ }^{16}$ At least ten countries have hosted national events to support dissemination of the action plan $^{[1]}$ while others participated in regional events. ${ }^{[2]}$

The comprehensive tool developed to support national tracking against the ENAP milestones and targets was completed by 10 of the 20 focus countries (Bangladesh, Ethiopia, Indonesia, Kenya, Malawi, Myanmar, Nigeria, Philippines, Tanzania and Vietnam). The tool was intended to assess status of progress, identify barriers to implementation and map specific technical assistance needs in each country. Results showed significant progress on action plan development and inclusion of commodities in essential medicines lists. Presence of multiple partners working on maternal and newborn health and numerous advocacy events were noted. The areas with the least progress identified included maternal death surveillance and response, perinatal audit, prioritization of research, and development/adaptation of local MNH devices. The technical assistance needs were mostly around support required for costing and budgeting of the action plans and guidance on perinatal audits. Around $10 \%$ of all responses (15 indicators) were not completed (Webannex A).

National newborn action plans or sharpened RMNCAH plans to incorporate newborn health are an important entry point to address newborn health in countries but are just one component towards process. ${ }^{417}$ Darmstadt and colleagues assessed progress across a policy heuristic, and found partial progress or major advances in the past decade in the areas of agenda setting, policy formulation and adoption, leadership and partnership; however, minimal progress was found for program implementation and evaluation. An assessment of benchmarks for readiness to integrate and scale up

\footnotetext{
${ }^{[1]}$ E.g. China, Ethiopia, Ghana, India, Nigeria, Pakistan, Rwanda, South Africa, Uganda

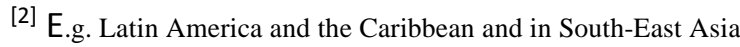


newborn survival interventions in nine countries found that only three had achieved above $75 \%$ of the benchmarks by 2010 , such as agenda setting (e.g. having a national newborn survival needs assessment), policy formulation (e.g. the national essential drugs list includes injectable antibiotics at primary care level) and policy implementation (e.g. standards for care of sick newborns exist at district hospital level). ${ }^{18} \mathrm{~A}$ bottleneck analysis of the high impact interventions for newborn survival around the time of birth and for small and sick newborns undertaken in 12 countries further informs our understanding of implementation barriers. ${ }^{14,15,19-24}$ The most significant bottlenecks to implementation of interventions were found for those which are more facility-based and require rapid emergency care, particularly for inpatient care of small and sick newborns, antenatal corticosteroids, treatment of neonatal infections and kangaroo mother care. ${ }^{20}$

Despite little programme learning published on scaling up of newborn health interventions, we know that context-specific approaches are necessary for countries to move from agenda setting and policy formulation to implementation. ${ }^{4,16,20}$ South Africa provides a strong and unique example of moving from policy to implementation prior to ENAP (Panel 2).

\section{Mechanisms to support country implementation}

Partnerships of key actors in national systems for health care delivery at scale have been critical for progress; likewise, coordinated efforts of global partners working in countries has helped to facilitate progress. ${ }^{4,17}$ To help inform countries (particularly Ministries of Health) as well as partners on a more complete picture of ongoing activities by other organizations, we undertook a partner mapping exercise. By March 2015, the activities of 47 partners were gathered in a simple database, which was validated by WHO. Within the limited sample of this first phase of mapping, there were cases where the current plans of one organisation were duplications of the plans of another organisation and both actors were unaware of each other's activity until it was brought to their attention through this exercise. Organisations reported that they had used the existing simple database to plan work and to partner with organisations in geographic districts that they had not an existing presence but had funding to extend activity to. The findings also showed that there is uneven attention across the components of the health system building blocks. For example, there is a large amount of technical support to health workforce training in the form of curriculum development and the training of trainers. However, health financing, identified as a significant barrier to the country implementation of the highest impact interventions, stands out with a very low level of technical support reported. ${ }^{20}$

The feedback from partners on this initial mapping exercise indicates the initiative to be very valuable; partners expressed full support for the ongoing mapping to provide information and data to inform their in-country decision-making. All partners reported that they do not have enough knowledge of the activities of other partners in-country, even though gathering such information is an essential task undertaken as part of their work. Partners reported that this process is done through networking and a central repository is far more efficient.

Multilaterals and bilaterals continue to support country implementation through a variety of mechanisms such as training modules and tools, research collaboration and global development alliances. For example, the Survive and Thrive Global Development Alliance has been a successful private-public partnership for maternal and newborn health. This has resulted in the expansion of the Helping Babies Breathe program that has been introduced in 77 countries with evidence of effect (Panel 3)..$^{25-27}$ 
UN agencies, particularly WHO and UNICEF, support countries in their implementation of newborn health programs through meetings of stakeholders in order to provide technical assistance, support and review country progress and disseminate technical guidelines. For example, a regional meeting was organized in Colombo, Sri Lanka from 11-13 November 2014 to develop common understanding for universal implementation of postnatal care for mothers and newborns in member countries of the region. At this meeting, countries agreed to finalize their costed national newborn action plans and adopt (or adapt) WHO postnatal care guidelines ${ }^{28}$ for implementation by December 2015. In Amman, in March 2015, the neonatal programme manager in 20 countries in the region undertook a gap analysis of neonatal health plans and reviewed existing plans to ensure alignment with ENAP and prepared and prepared key neonatal health actions required to fill existing gaps. Regional campaigns such as the Campaign on Accelerated Reduction of Maternal Mortality in Africa ${ }^{29}$ and the First Embrace campaign in the Western Pacific Region ${ }^{30}$ can be used to mobilize action in counties to advance best practices for newborn health, including the shifting of cultural norms, behaviour change and better accountability for actions to achieve ENAP milestones.

Country efforts are also supported by global advocacy initiatives. For example, World Prematurity Day started in 2011 , led by a coalition of primarily parent groups in a few countries. Since 2012 , a coalition of global partners has developed a toolkit for national use including core messages, template press releases, ideas for activities, fact sheets, powerpoints, country data, infographics, and customizable templates (posters, petitions, banners, badges), among other materials. As a result, more countries are participating with events documented in over 70 countries in 2014, ${ }^{16,31}$ of which more than 13 national governments were engaged in activities, including some with parliamentarians and Ministers of Health. Also, at least 150 landmarks around the globe were lit purple in support of World Prematurity Day, including Niagara Falls, The Empire State Building in New York City, Mexico's Federal Congress and Ministry of Health, and the Bosphorus Strait Bridge in Istanbul. The global media coverage alone reached almost 2 billion people worldwide. ${ }^{32}$ World Breastfeeding Week also resonates in countries resulting in national-level awareness campaigns advocating for change. ${ }^{16} \mathrm{Global}$ movements and collective actions support accountability efforts and raise awareness to engaged audiences to support implementation efforts.

\section{Finances for newborn health}

A recent financing analysis shows a modest rising trend in official development assistance (ODA) mentioning newborn health, but also found that only $10 \%$ of all ODA for $\mathrm{MNCH}$ mentioned newborn search terms and only about $4 \%$ of child health investment was going to newborn health. ${ }^{4}$ The new Global Investment Framework for Women's and Children's health clearly shows that evidence-based maternal and newborn interventions are cost-effective, affordable and deliver a high return in both health and economic terms. ${ }^{33}$ The integrated investment case for women's and children's health is strong and existing platforms must be used to channel funds towards these critical investments.

The past year has seen increasing investment and commitment towards maternal and newborn health with approximately 50 financing, policy and service delivery commitments announced at the launch of ENAP, showcasing multi-stakeholder interest and recognition of the previous gap in investments. ${ }^{16}$ For example, the Islamic Development Bank launched the "Save the Mothers" initiative, which will provide financing totalling US\$90 Million to improve maternal and newborn health in 56 member countries in Sub-Saharan Africa. ${ }^{34}$ In addition, the private sector has contributed 17 new commitments valued at over US\$100 million, representing over $40 \%$ of all new commitments and the single largest private sector contribution recorded for the launch of a new global health initiative. In addition to these new commitments, at least 40 other companies have investments that are contributing to improvements in 
the health and development of newborns all over the world. ${ }^{35}$ By May 2014, total financial commitments to the Global Strategy for Women's and Children's Health rose to \$60 million with over half already disbursed since $2010 .^{1}$

National tracking of newborn health spending remains a gap without resolve. The National Health Accounts system subaccounts for reproductive and child health both include components of newborn health; reproductive health subaccounts captures advice on birth spacing and birth control, antenatal care, safe delivery, breastfeeding counselling and immediate postnatal care whereas the child health subaccount only captures expenditures that target the child and that are provided after birth. ${ }^{36,37}$ The guidelines even indicate this limitation, "in many settings, newborn care is delivered in conjunction with maternal care, and it may be difficult to disentangle the expenditures for the child." ${ }^{36}$ Given services for newborn are often done in conjunction with the mother, as they should be programmatically, it is difficult to separate expenditure. However, without disaggregated data it will be impossible to determine if national spending is appropriately balanced across the continuum of care and aligned with national priorities. Also the subaccount data is not publically accessible through the online Global Health Expenditure Database. ${ }^{38}$

\section{Newborn health related interventions}

Recent evidence reviews for newborn health indicate that the efficacy and effectiveness research provides solid evidence of feasible, high impact interventions that can be expected to significantly improve newborn survival and health and stillbirth reduction in developing countries. ${ }^{7}$ Effective approaches to deliver these interventions at scale within different health system contexts have also been tested, demonstrating that a variety of approaches can be taken effectively. Evidence now supports global consensus on a basic set of immediate care interventions that all newborns should receive - including thermal protection, clean cord care, and immediate and exclusive breastfeeding which should be provided whether babies are delivered in communities or at any level of health facility. ${ }^{39}$ Field studies ${ }^{40-44}$ have proven that these basic interventions can be effectively delivered in developing country communities and households and can achieve significant improvement in newborn survival even in the absence of curative care.

Research has also identified the major causes of death for babies during birth and the newborn period, ${ }^{45}$ as well as interventions to prevent or treat these conditions (Table 2). Packages" of these interventions have also been developed, tested, and demonstrated to be effective under varying circumstances. The terminology, programmatic approach, systems support, and degree of integration with other health activities of these packages may be country-specific. For babies born in communities packages include community-based essential newborn care, ${ }^{42,46,47}$ postnatal care through home visits (both often integrated with maternal care services) ${ }^{41,42,47}$ community-based detection and treatment/referral of possible severe bacterial infection. ${ }^{48}$ For babies born in facilities, packages include essential newborn care, ${ }^{49}$ resuscitation ("Helping Babies Breathe"), ${ }^{50,51} \mathrm{KMC}^{52}$ and postnatal home visits after discharge.

Beyond these tested "packages," several evidence-based interventions with demonstrated potential for impact have not yet been mainstreamed into newborn care programming, making introduction and evaluation in actual program settings a high priority, such as chlorhexidine cord cleansing, simplified antibiotic regimens for severe infections, and community-based management of severe infections. ${ }^{53-58}$ There is also a pipeline of new, potentially feasible and effective interventions that need to be applied and evaluated in program settings, including: simplified resuscitation devices designed for lower skilled health workers; improved technologies for monitoring fetal status during labor; "checklists" to improve 
quality of maternal and newborn care; topical emollient therapy for preterm infants; KMC in community settings; and antibiotics in pre-filled injection devices for treatment of newborn infection by community health workers.

Even for interventions with strong evidence, slow coverage increases as compared with adoption rates for other global health innovations further indicate the need to focus on country implementation using the knowledge we currently have (Figure 1). ${ }^{20}$ Beyond understanding system bottlenecks, unpacking and responding to community perceptions, beliefs and practices are a cornerstone for supporting scale up of these interventions. New WHO guidelines on community mobilization and health promotion interventions provide the knowledge required to advance efforts in countries for scaling up these services and engaging communities. ${ }^{59,60}$

\section{Newborn health related indicators}

Efforts to advance metrics has focused on highlighting major information and data gaps for newborn health, especially for tracking implementation progress through measuring the coverage of high impact, evidence-based interventions. A multistage consultation process carried out between 2013 and 2014 identified 10 core ENAP indicators and a set of additional indicators for care at and around the time of birth. Three of these core indicators measure impact (maternal mortality ratio, neonatal mortality rate and stillbirth rate) and already have standard indicator definitions, but a major drive is needed to improve the quality and quantity of the impact information in countries. The ENAP metrics consultation process found the greatest information gaps in coverage data, which is critical for measuring implementation progress. Coverage of care for all mothers and newborns (e.g., skilled birth attendance, early postnatal care, essential newborn care) have defined contact points, standard indicators and data are routinely collected, but information gaps exist in measuring the content and quality of these interactions. Five newborn-specific interventions (antenatal corticosteroids, kangaroo mother care, neonatal resuscitation, management of neonatal infections and chlorhexidine cord cleansing) do not have standard indicators or data that are comparable between settings. Such major data gaps hinder implementation progress despite the potential impact of the interventions on newborn morbidity and mortality and on reducing health inequities.

The ENAP metrics stream has devised a measurement improvement roadmap (2015-2020), a multipartner 5-year plan to validate and institutionalise the core ENAP indicators in national data collection platforms and global accountability mechanisms. ${ }^{16}$ The roadmap supports broader movement into the Sustainable Development Goal era to improve health information, including the Measurement for Accountability for Results in Health, with a focus on health monitoring, accountability and action. Overall, the plan will result in improved measurement of impact, coverage, quality and equity around the time of birth and outlines the specific tools needed to be developed such as death registration, audit, and defining a minimum perinatal dataset. The specific actions needed to test, validate and institutionalise proposed coverage indicators for measuring implementation progress in countries (with proposed country testing sites) are described in the ENAP metrics measurement improvement plan. ${ }^{61}$

\section{Conclusion}

Across the various streams of ENAP activities, lessons learned can be drawn from what has worked to support countries in their efforts to elevate this issue and scale up effective, known solutions to prevent newborn deaths and stillbirths (Table 3). An overarching theme is that the collective global effort has been helpful in terms of harmonizing partner efforts at country level. The long-term effects of the new tools developed will need further monitoring and tracking to determine if they are useful to countries in their efforts to improve newborn survival and reduce stillbirths. Implementation research is required for 
learning how to deliver and achieve effective coverage of these intervention packages at scale. The priority moving forward is to put into practice what we know works, particularly in the most challenging and hardest-to-reach settings, and document lessons learned. The impact of ENAP on increasing coverage of quality newborn health care and saving lives is yet to be determined and will require a strong monitoring and evaluation framework, which is still iunder development. ${ }^{62}$

Nonetheless, the MDGs demonstrated that the global community can set ambitious targets and work together over a sustained period of time to accelerate progress towards those targets. This same principle is the hope of ENAP. These issues are intrinsically linked with the survival, health and nutrition of women before conception and during and between pregnancies; therefore efforts in countries should also consider the targets and goals set in Strategies Toward Ending Preventable Maternal Mortality $\left(\right.$ EPMM $^{63}$ released in February 2015, as well as link into the new Global Strategy for Women's, Children's and Adolescents' Health to be launched in September this year. ${ }^{1}$ Continued efforts as a global community to support country efforts will be critical for women's and children's health and mothers, newborns and stillbirths sit at the centre of this continuum. 
List of abbreviations: CARMMA - Campaign on Accelerated Reduction of Maternal Mortality in Africa, DCSTs - District Clinical Specialist teams, ENAP - Every Newborn Action Plan, EPMM - Ending Preventable Maternal Mortality, HBB - Helping Babies Breathe, GDA - Global Development Alliance, HBS - Helping Babies Survive, KMC - Kangaroo Mother Care, MDG - Millennium Development Goals, $\mathrm{MNCH}$ - Maternal, Newborn, Child Health, $\mathrm{MOH}$ - Ministry of Health, MSSN - management of the small and sick newborn, NaPeMMCo - National Perinatal Morbidity and Mortality Committee, NICHD National Institute of Child Health and Development, NNCC - National Neonatal Coordinating Committee, ODA - Official development assistance, RMNCAH - Reproductive, Maternal, Newborn, Child Health, UNICEF - United Nations Children's Fund, USAID - United States Agency for International Development, WHA - World Health Assembly, WHO - World Health Organization.

\section{Funding statement}

Analyses described in this paper were supported through a grant to the United States Fund for the United Nations Children's Fund from the Bill \& Melinda Gates Foundation with additional support from Save the Children's Saving Newborn Lives Program, the Children's Investment Fund Foundation and the United States Agency for International Development.

Competing interests: None

Authors' contributions: The authors have not declared competing interests.

\section{Authors' information: See top}

\section{Acknowledgements:}

This work would not have been possible without the efforts of those working in countries to implement the Every Newborn Action Plan. We appreciate those who have completed the country implementation tools, particularly the support of the UNICEF country and regional offices in completing the modified tracking tool and the WHO regional and country offices and partners providing reviews and updates for the mapping exercise. We would like to thank the Every Newborn management team and the four main implementation groups: country implementation, metrics, advocacy and research for their support and efforts. We also acknowledge the following individuals for their contributions: Offeibea Obubah, Ashek Ahmed, Anita Sharma, Lee Pyne-Mercier, and Joy Riggs-Perla. 


\section{REFERENCES}

1. Every Woman Every Child. Saving lives protecting future: Progress Report on the Global Strategy for Women's and Children's Health 2010-2015. Italy: Every Woman Every Child; 2015. (http://everywomaneverychild.org/global-strategy-2/gs2-progress-report).

2. Jamison DT, Summers LH, Alleyne G, et al. Global health 2035: a world converging within a generation. Lancet. 2013;382:1898-1955.

3. UN Inter-agency Group for Child Mortality Estimation (IGME). Levels and trends in child mortality: Report 2014. New York, USA: UNICEF; 2014. (www.childmortality.org).

4. Darmstadt GL, Kinney MV, Bhutta ZA, et al. Who has been caring for the newborn? Lancet. 2014;doi:10.1016/S0140-6736(14)60458-X.

5. WHO, UNICEF, UNFPA, The World Bank, United Nations Population Division. Trends in maternal mortality: 1990-2013. Geneva, Switzerland: World Heath Organization; 2014. (http://www.who.int/reproductivehealth/publications/monitoring/maternal-mortality2013/en/l).

6. Cousens $\mathrm{S}$, Blencowe $\mathrm{H}$, Stanton $\mathrm{C}$, et al. National, regional, and worldwide estimates of stillbirth rates in 2009 with trends since 1995: a systematic analysis. Lancet. 2011;377:1319-1330.

7. Bhutta ZA, Das JK, Bahl R, et al. What will it take to avert preventable newborn deaths and stillbirths and at what cost? Lancet. 2014;doi:10.1016/S0140-6736(14)60792-3.

8. Mason EM, McDougall L, Gupta A, et al. From evidence to action to deliver a healthy start for the next generation. Lancet. 2014; doi:10.1016/S0140-6736(14)60750-9.

9. UN-IGME. Levels and trends in child mortality: Report 2014. New York, USA: UN-Interagency group for child mortality estimation; 2014.

(http://www.unicef.org/media/files/Levels and Trends in Child Mortality 2014.pdf).

10. Lawn JE, Kinney MV, Black RE, et al. Newborn survival: a multi-country analysis of a decade of change. Health policy and planning. 2012;27 Suppl 3:iii6-28.

11. UNICEF, WHO. Every Newborn: An action plan to end preventable deaths. Geneva: World Health Organization; 2014. (http://www.everynewborn.org/every-newborn-action-plan/).

12. WHA67.10 R. Newborn health action plan. Geneva: World Health Assembly; 2014.

13. Dickson K, Simen Kapeu A, Huicho L, et al. Every Newborn: Country bottlenecks and success factors. Lancet. 2014.

14. Moxon SG, Deorari A, Singhal N, et al. PLACEHOLDER: Inpatient care for small and sick newborns: A multi-country analysis of health system bottlenecks and potential solutions. BMC Pregnancy Childbirth. 2015.

15. Simen-Kapeu A, Wall S, Dickson K, Moxon SG, Lawn J, Seale A. PLACEHOLDER: Management of neonatal infections: A multi-country analysis of health system bottlenecks and potential solutions. BMC Pregnancy Childbirth. 2015.

16. WHO, UNICEF. Every Newborn Progress Report 2015. Geneva: World Health Organization; 2015.

17. Darmstadt GL, Oot DA, Lawn JE. Newborn survival: changing the trajectory over the next decade. Health policy and planning. 2012;27 Suppl 3:iii1-5.

18. Moran AC, Kerber K, Pfitzer A, et al. Benchmarks to measure readiness to integrate and scale up newborn survival interventions. Health policy and planning. 2012;27 Suppl 3:iii29-39.

19. Dickson KE, Simen-Kapeu A, Kinney MV, et al. Every Newborn: health-systems bottlenecks and strategies to accelerate scale-up in countries. Lancet. 2014;384:438-454.

20. Dickson K, Kinney M, Moxon SG, et al. PLACEHOLDER REFERENCE: Quality of care at and around the time of birth and for care of small and sick newborns: a multi-country analysis of health system bottlenecks and potential solutions: Paper 1 of 9. BMC Pregnancy Childbirth. 2015. 
21. Sharma G, al. E. PLACEHOLDER REFERENCE: Quality essential care during labour and birth: A multi-country analysis of health system bottlenecks and potential solutions. Paper 2 of 9. BMC Pregnancy Childbirth. 2015.

22. Liu G, Segre J, Dickson K, et al. PLACEHOLDER: Antenatal corticosteroids for the management of preterm birth: A multi-country analysis of health system bottlenecks and potential solutions

BMC Pregnancy Childbirth. 2015.

23. Enweronu-Laryea C, Moxon SG, Simen-Kapeu A, et al. PLACEHOLDER: Basic Newborn Care and neonatal resuscitation:A multi-country analysis of health system bottlenecks and potential solutions

BMC Pregnancy Childbirth. 2015.

24. Vesel L, Bergh AM, Kerber K, et al. PLACEHOLDER Kangaroo Mother Care: A multi-country analysis of health system bottlenecks and potential solutions. BMC Pregnancy Childbirth. 2015.

25. Msemo G, Massawe A, Mmbando D, et al. Newborn mortality and fresh stillbirth rates in Tanzania after helping babies breathe training. Pediatrics. 2013;131:e353-360.

26. Goudar SS, Somannavar MS, Clark R, et al. Stillbirth and newborn mortality in India after helping babies breathe training. Pediatrics. 2013;131:e344-352.

27. Kak LP, Johnson J, McPherson R, Keenan W, Schoen E. Helping Babies Breathe: Lessons learned guiding the way forward. A 5-year report from the HBB Global Development Alliance: Survive and Thrive; 2015. (http://www.healthynewbornnetwork.org/sites/default/files/resources/HBB\%20report\%202010 -2015\%20FINAL.pdf).

28. World Health Organization. WHO recommendations: Postnatal care of mother and newborn. Geneva, Switzerland: WHO; 2013. (http://www.healthynewbornnetwork.org/sites/default/files/resources/Postnatal Care Guideli nes web v2.pdf).

29. CARMMA, African Union. Why Campaign on Accelerated Reduction of Maternal Mortality in Africa (CARMMA)? 2012. (http://carmma.org/page/why-carmma).

30. WHO-WPRO. First Embrace. 2014. (http://thefirstembrace.org/).

31. Blencowe H, McDougall L, Kinney M, Cousens S, Lawn JE. 15 million babies "Born too soon" Parents, professionals and politicians come together to amplify the evidence through media and public events. In: Medicine LSoHT, ed. Maximising Research Impact. London, UK: LSHTM; 2013.

32. Lawn JE, Kinney M. Preterm birth: now the leading cause of child death worldwide. Science translational medicine. 2014;6:263ed221.

33. Stenberg $\mathrm{K}$, Axelson $\mathrm{H}$, Sheehan $\mathrm{P}$, et al. Advancing social and economic development by investing in women's and children's health: a new Global Investment Framework. Lancet. 2013;383:1333-1354.

34. Islamic Development Bank. Every Woman Every Child commitments: Islamic Development Bank. 2014. (http://www.everywomaneverychild.org/commitments/all-commitments/islamicdevelopment-bank).

35. GBCHealth, The MDG Health Alliance. The Ultimate Investment in the Future Profiles of Corporate Engagement in the Health and Development of Newborns. New York, NY: GBCHealth; 2015. (http://www.gbchealth.org/wp-content/uploads/2015/05/The-Ultimate-InvestmentCorporate-Newborn-Publication ReducedSize.pdf).

36. WHO. Guide to producing reproductive health subaccounts within the national health accounts framework. Geneva, Switzerland: World Health Organizaion; 2009. (http://whqlibdoc.who.int/publications/2009/9789241598538 eng.pdf?ua=1). 
37. WHO. Guide to producing child health subaccounts within the national accounts frameworks. Geneva, Switzerland: World Health Organization; 2012. (http://apps.who.int/iris/bitstream/10665/104202/1/9789241503013 eng.pdf?ua=1).

38. World Health Organization. National Health Accounts. 2013. (http://www.who.int/entity/nha/).

39. WHO. Guidelines on maternal, newborn, child and adolescent health approved or under review by the WHO guidelines review committee: Recommendations on newborn health. Gevena, Switzerland: World Health Organization; 2013. (http://www.who.int/maternal child adolescent/documents/guidelines-recommendationsnewborn-health.pdf).

40. Bhutta ZA, Soofi S, Cousens $S$, et al. Improvement of perinatal and newborn care in rural Pakistan through community-based strategies: a cluster-randomised effectiveness trial. Lancet. 2011;377:403-412.

41. Baqui AH, El-Arifeen S, Darmstadt GL, et al. Effect of community-based newborn-care intervention package implemented through two service-delivery strategies in Sylhet district, Bangladesh: a cluster-randomised controlled trial. Lancet. 2008;371:1936-1944.

42. Kumar V, Mohanty S, Kumar A, et al. Effect of community-based behaviour change management on neonatal mortality in Shivgarh, Uttar Pradesh, India: a cluster-randomised controlled trial. Lancet. 2008;372:1151-1162.

43. Kirkwood BR, Manu A, Tawiah-Agyemang C, et al. NEWHINTS cluster randomised trial to evaluate the impact on neonatal mortality in rural Ghana of routine home visits to provide a package of essential newborn care interventions in the third trimester of pregnancy and the first week of life: trial protocol. Trials. 2010;11:58.

44. Tomlinson $\mathrm{M}$, Doherty $\mathrm{T}$, Jackson $\mathrm{D}$, et al. An effectiveness study of an integrated, communitybased package for maternal, newborn, child and HIV care in South Africa: study protocol for a randomized controlled trial. Trials. 2011;12:236.

45. Liu L, Oza S, Hogan D, et al. Global, regional, and national causes of child mortality in 2000-13, with projections to inform post-2015 priorities: an updated systematic analysis. Lancet. 2014.

46. Bang AT, Bang RA, Reddy HM. Home-based neonatal care: summary and applications of the field trial in rural Gadchiroli, India (1993 to 2003). J.Perinatol. 2005;25 Suppl 1:S108-S122.

47. Bhutta ZA, Memon ZA, Soofi S, Salat MS, Cousens S, Martines J. Implementing community-based perinatal care: results from a pilot study in rural Pakistan. Bull World Health Organ. 2008;86:452-459.

48. Zaidi AK, Ganatra HA, Syed S, et al. Effect of case management on neonatal mortality due to sepsis and pneumonia. BMC Public Health. 2011;11 Suppl 3:S13.

49. WHO. Essential newborn care training course. Geneva: World Health Organization; 2010.

50. Lee AC, Cousens S, Wall SN, et al. Neonatal resuscitation and immediate newborn assessment and stimulation for the prevention of neonatal deaths: a systematic review, meta-analysis and Delphi estimation of mortality effect. BMC Public Health. 2011;11 Suppl 3:S12.

51. Singhal $\mathrm{N}$, Lockyer J, Fidler $\mathrm{H}$, et al. Helping Babies Breathe: global neonatal resuscitation program development and formative educational evaluation. Resuscitation. 2012;83:90-96.

52. Lawn JE, Mwansa-Kambafwile J, Horta BL, Barros FC, Cousens S. 'Kangaroo mother care' to prevent neonatal deaths due to preterm birth complications. Int J Epidemiol. 2010;39 Suppl 1:i144-154.

53. African Neonatal Sepsis Trial g, Tshefu A, Lokangaka A, et al. Oral amoxicillin compared with injectable procaine benzylpenicillin plus gentamicin for treatment of neonates and young infants with fast breathing when referral is not possible: a randomised, open-label, equivalence trial. Lancet. 2015;385:1758-1766. 
54. Imdad A, Bautista RM, Senen KA, Uy ME, Mantaring JB, 3rd, Bhutta ZA. Umbilical cord antiseptics for preventing sepsis and death among newborns. Cochrane Database Syst Rev. 2013;5:CD008635.

55. African Neonatal Sepsis Trial g, Tshefu A, Lokangaka A, et al. Simplified antibiotic regimens compared with injectable procaine benzylpenicillin plus gentamicin for treatment of neonates and young infants with clinical signs of possible serious bacterial infection when referral is not possible: a randomised, open-label, equivalence trial. Lancet. 2015;385:1767-1776.

56. Bang AT, Bang RA, Baitule SB, Reddy MH, Deshmukh MD. Effect of home-based neonatal care and management of sepsis on neonatal mortality: field trial in rural India. Lancet. 1999;354:1955-1961.

57. Baqui $\mathrm{AH}$, Arifeen SE, Williams EK, et al. Effectiveness of home-based management of newborn infections by community health workers in rural Bangladesh. Pediatr Infect Dis J. 2009;28:304310.

58. Khanal S, Sharma J, Gc VS, et al. Community health workers can identify and manage possible infections in neonates and young infants: MINI--a model from Nepal. J Health Popul Nutr. 2011;29:255-264.

59. WHO. WHO recommendation on community mobilization through facilitated participatory learning and action cycles with women's groups for maternal and newborn health. Geneva, Switzerland: World Health Organization; 2014. (http://apps.who.int/iris/bitstream/10665/127939/1/9789241507271 eng.pdf?ua=1).

60. WHO. WHO recommendations on health promotion interventions for maternal and newborn health. Geneva: World Health Organization; 2015.

(http://www.who.int/maternal child adolescent/documents/health-promotioninterventions/en/).

61. Moxon SG, Kerber K, Lawn JE, al. E. PLACEHOLDER: Count Every Newborn: A measurement improvement roadmap. BMC Pregnancy Childbirth. 2015.

62. WHO. EB137/4 Newborn health: draft accountability framework. Geneva, Switzerland: World Health Organization; 2015. (http://apps.who.int/gb/ebwha/pdf files/EB137/B137 4-en.pdf).

63. WHO. Strategies toward ending preventable maternal mortality (EPMM). Geneva: World Health Organization; 2015. (http://who.int/reproductivehealth/topics/maternal perinatal/epmm/en/).

64. Dorrington RE, Bradshaw D, Laubscher R, Nannan N. Rapid mortality surveillance report 2013. Cape Town: South African Medical Research Council; 2014.

65. Velaphi S, Rhoda N. Reducing neonatal deaths in South Africa - are we there yet, and what can be done? SA Journal of Child Health. 2012;6:67-71.

66. Pattinson RC, Rhoda N. Saving babies 2012-2013: Ninth report on perinatal care in South Africa. Pretoria: Tshepesa Press; 2014. (http://www.ppip.co.za/wp-content/uploads/Saving-Babies2012-2013.pdf).

67. Pattinson R, Makin JD, Pillay Y, Van Den Broek N, Moodley J. Basic and comprehensive emergency obstetric and neonatal care in 12 South African health districts. SAMJ. 2013;105:256260.

68. Chola L, Pillay Y, Barron P, Tugendhaft A, Kerber K, Hofman K. Cost and impact of scaling up interventions to save lives of mothers and children: taking South Africa closer to MDGs 4 and 5. Glob Health Action. 2015;8:27265.

69. NAPEMMCO. National Perinatal Morbidity and Mortality Committee report 2008-2010. Pretoria: National Department of Health; 2011.

70. Department of Health. Strategic Plan for Maternal, Newborn, Child and Women's Health (MNCWH) and Nutrition in South Africa. Pretoria: Republic of South Africa; 2012. 
(https://extranet.who.int/nutrition/gina/sites/default/files/ZAF\%202012\%20MNCWHstratplan.p df).

71. WHO. World Health Statistics 2014. Geneva: World Health Organization; 2014. (http://www.who.int/gho/publications/world health statistics/2014/en/).

72. UNICEF. State of the World's Children. New York, USA: UNICEF; 2013.

73. Mahy M, Tassie JM, Ghys PD, et al. Estimation of antiretroviral therapy coverage: methodology and trends. Current opinion in HIV and AIDS. 2010;5:97-102.

74. Grabowski H, Vernon J, DiMasi JA. Returns on research and development for 1990s new drug introductions. PharmacoEconomics. 2002;20 Suppl 3:11-29.

75. Mwansa-Kambafwile J, Cousens S, Hansen T, Lawn JE. Antenatal steroids in preterm labour for the prevention of neonatal deaths due to complications of preterm birth. Int J Epidemiol. 2010;39 Suppl 1:i122-133.

76. WHO. Guidelines on optimal feeding of low birth weight infants in low and middle income countries. . Geneva: World Health Organization; 2011. (http://www.who.int/maternal child adolescent/documents/infant feeding low bw/en/index. html).

77. Hofmeyr GJ, Haws RA, Bergstrom S, et al. Obstetric care in low-resource settings: what, who, and how to overcome challenges to scale up? Int J Gynaecol Obstet. 2009;107 Suppl 1:S21-44, S44-25.

78. Blencowe $\mathrm{H}$, Cousens $\mathrm{S}$, Mullany LC, et al. Clean birth and postnatal care practices to reduce neonatal deaths from sepsis and tetanus: a systematic review and Delphi estimation of mortality effect. BMC Public Health. 2011;11 Suppl 3:S11.

79. Bhutta ZA, Ahmed T, Black RE, et al. What works? Interventions for maternal and child undernutrition and survival. Lancet. 2008;371:417-440.

80. Lamberti LM, Fischer Walker CL, Noiman A, Victora C, Black RE. Breastfeeding and the risk for diarrhea morbidity and mortality. BMC Public Health. 2011;11 Suppl 3:S15.

81. Garcia CR, Mullany LC, Rahmathullah L, et al. Breast-feeding initiation time and neonatal mortality risk among newborns in South India. J Perinatol. 2011;31:397-403.

82. Mullany LC, Katz J, Li YM, et al. Breast-feeding patterns, time to initiation, and mortality risk among newborns in southern Nepal. The Journal of nutrition. 2008;138:599-603.

83. Mullany LC, Darmstadt GL, Khatry SK, et al. Topical applications of chlorhexidine to the umbilical cord for prevention of omphalitis and neonatal mortality in southern Nepal: a communitybased, cluster-randomised trial. Lancet. 2006;367:910-918.

84. Arifeen SE, Mullany LC, Shah R, et al. The effect of cord cleansing with chlorhexidine on neonatal mortality in rural Bangladesh: a community-based, cluster-randomised trial. Lancet.

2012;379:1022-1028. 


\section{Panel 1: Every Newborn vision, goals, guiding principles and strategic objectives Vision}

A world in which there are no preventable deaths of newborns or stillbirths, where every pregnancy is wanted, every birth celebrated, and women, babies and children survive, thrive and reach their full potential.

\section{Goals}

Goal 1: End preventable newborn deaths.

By 2030, all countries will reach the target of 12 or less newborn deaths per 1000 live births and continue to reduce death and disability, ensuring that no newborn is left behind.

Goal 2: End preventable stillbirths.

By 2030 , all countries will reach the target of 12 or less stillbirths per 1000 total births and continue to close equity gaps.

Guiding principles: Country leadership, Human rights, Integration, Equity, Accountability, Innovation

\section{Strategic objectives}

1. Strengthen and invest in care during labor, birth and the first day and week of life.

2. Improve the quality of maternal and newborn care.

3. Reach every woman and newborn to reduce inequities.

4. Harness the power of parents, families and communities.

5. Count every newborn through measurement, program-tracking and accountability.

\section{National milestones}

National plans: Sharpened national strategies, policies and guidelines for RMNCAH.

Data: Count every newborn by improving and using programmatic coverage data including equity and quality gap assessments.

Quality: Adopt Every Mother Every Newborn Quality Initiative standards and ensure commodity availability.

Investment: Develop or integrate costed human resources for addressing newborn health and stillbirths into RMNCAH plans and ensure sufficient financial resources are allocated.

Health workers: Ensure the training, deployment and support of health workers, in particular midwifery personnel, nurses and community health workers.

Innovation and Research: Develop, adapt and promote access to devices and commodities and agree on and invest in prioritized research.

Engagement: Involve communities, civil society and other stakeholders to increase demand and ensure access and coverage of essential maternal and newborn care.

Parent voices and champions: Shift social norms so that it is no longer acceptable for babies to die needlessly just as it has become unacceptable for women to die giving birth. 


\section{Panel 2: SOUTH AFRICA SCALES UP NEWBORN CARE}

The Call to Action presented in The Lancet Every Newborn Series identified five things countries needed to do differently to address newborn survival and health: leadership and more coordinated partnerships, parent voice, investment, implementation and indicators with effective data collection and accountability. ${ }^{8}$ South Africa provides a strong example across all of these elements prior to ENAP. Despite high coverage of skilled birth attendance and institutional delivers ( $>90 \%)$, resulting from investment by the government in health facilities, the rate of reduction in neonatal mortality over the last decade has been minimal (1.3\% annual decline according to the UN estimates ${ }^{3}$ but even lower when using national estimates) ${ }^{64}$, partly due to the restructuring of the apartheid health system, attrition in the nursing cadre and the HIV pandemic. ${ }^{65}$ The majority of neonatal deaths are intrapartum-related, or due to complications from preterm birth or infections. ${ }^{66}$ South Africa is not on track to achieve the MDGs for women's and children's health due to challenges of equity and quality of care, such as provision of emergency obstetric care. ${ }^{66,67}$ Nonetheless, the country has made substantial progress nationally towards identifying gaps and prioritizing interventions for scaling up maternal and newborn care with specific emphasis on improving the quality of care. ${ }^{68}$

\section{Intentional leadership and partnership}

The South African government showed national commitment to the MDGs by establishing three Ministerial Committees for maternal, neonatal and children's deaths in 2008. The committees, led by local experts and specialists, presented key findings and recommendations to the National Health Council in 2011. ${ }^{66,68}$ In 2012, the National Newborn Implementation and Monitoring Plan for South Africa, endorsed by the National Department of Health (NDOH) and supported by UNICEF, incorporated the National Perinatal Mortality and Morbidity Committee (NaPeMMCo) recommendations. ${ }^{69}$

To support implementation of these new policies, the NDOH appointed a neonatal care improvement advisor, funded by UK AID, as the focal newborn care person in 2013. NDOH also established a National Neonatal Coordinating Committee (NNCC) with oversight responsibility for coordinating, guiding and shaping the input from partners, which has strengthened the common vision and goal of partners to reduce maternal and perinatal deaths.

\section{Indicators}

The national strategy focuses on six priority interventions for reducing newborn mortality: promotion of early and exclusive breastfeeding, provision of prevention of mother-to-child transmission of HIV, resuscitation of newborns, care for small/ill newborns, Kangaroo Mother Care, and postnatal visits within six days. ${ }^{70}$ These interventions have been packaged into three interventions for national roll out, that focus on the leading causes of newborn deaths: Helping Babies Breathe (HBB), management of the small and sick newborn (MSSN), and providing continuous positive airway pressure (CPAP) at targeted district hospitals where premature deaths are highest. Nationally, 15 core indicators have been identified for a monitoring Maternal, Newborn and Child Health (MNCH) framework, established as part of the African Union Campaign to Accelerate Reduction of Maternal, Neonatal and Child Mortality in Africa (CARMMA) and the Countdown to 2015 initiative - three of which are related to perinatal health: stillbirth rate in facilities, neonatal mortality rate in facilities, and rate of livebirths under $2500 \mathrm{~g}$ in facilities. These indicators are tracked from facility to national level.

\section{Implementation}

National roll out of the intervention packages is underway with particular focus on district hospitals were most births and deaths occur. Critical to success has been the establishment of the District Clinical 
Specialist teams (DCSTs), consisting of doctors (pediatrician, obstetrician, anesthetist, family physician) and nurses (primary health care nurse, midwife and pediatric nurse) who work in dyads to improve maternal and child health. These teams, formed in all districts in 2012 as part of the NaPeMMCo recommendations, oversee, guide and are the master trainers of the targeted interventions; their job is to improve the quality of care for $\mathrm{MNCH}$. Effective implementation hinges on the frontline workers performing their duties with good attitudes and having the appropriate skills. DCSTs are also primarily responsible for clinical governance at district level.

\section{Investment}

Funding for the implementation of the newborn care strategic interventions has been successfully secured via the NNCC partners (global and national) and has included the provision of HBB manikins, research for implementation of $\mathrm{KMC}$, the provision of master trainers, the training of facilitators in both HBB and MSSN for national roll out and the costing of these newborn care interventions for the country.

\section{Parent voices for action}

In 2012, South Africa launched a campaign called "South Africa Cares: No Woman Should Die While Giving Life" as part of CARMMA to help accelerate existing strategies and programs to improve $\mathrm{MNCH}$. In addition, every year since 2011, a growing number of hospitals and parent groups have participated in World Prematurity Day on November $17^{\text {th }}$, raising awareness around preterm birth, supporting affected families and generating media attention. Similar advocacy campaigns are planned in alignment with the country's existing health calendar events especially global KMC awareness day and breastfeeding week. 


\section{Panel 3: Helping Babies Survive: an Educational Program Supported by the Survive and Thrive Global Development Alliance to Accelerate Newborn Mortality Reduction}

Survive and Thrive is a public-private partnership that engages U.S. pediatric, Obstetrics/Gynecology, and midwifery membership associations, non-governmental organizations, the private sector and the United States Government to collaborate to help newborns, children and women survive and thrive. Founding partners include the United States Agency for International Development (USAID), the National Institute of Child Health and Development (NICHD), American Academy of Pediatrics, American College of Nurse Midwives, American College of Obstetrics and Gynecologists, Johnson and Johnson, Laerdal Global Health, Jhpiego, and Saving Newborn Lives/Save the Children.

The Survive and Thrive partners have been actively involved in contributing to the ENAP from its inception and, moving forward, in supporting countries to achieve their ambitious newborn mortality targets. An important contribution of the alliance is the development of a suite of training modules called "Helping Babies Survive" (HBS) which aims to improve clinical skills of health providers to prevent and manage the major causes of newborn deaths. Content and skills training of these modules have received guidance from WHO as well as extensive assistance from medical professionals of Africa, Asia and South America. The training methodology replicates the simplicity and practical hands-on approach of the successful Helping Babies Breathe (HBB) training program.

Quality improvement skills are an integral part of the HBS training program. During 2014 and 2015, master trainers from over 20 African and Asian countries were trained in regional workshops convened in Ethiopia and Bangladesh, respectively. Several country teams have developed plans to adapt and integrate the HBS modules into their existing newborn programs.

In support of the ENAP, Survive and Thrive and the professional associations of Ethiopia, India and Nigeria have entered into a partnership to support national efforts to Help 100,000 Babies Survive and Thrive. In addition to resources contributed by the above partners, the initiative has received support from the Norwegian Agency for Development Cooperation and the Bill and Melinda Gates Foundation.

\section{Helping Babies Breathe: Lessons Learned Guiding the Way Forward}

The HBB Global Development Alliance (GDA) demonstrated that global public-private partnership was an effective strategy to support the implementation of a specific health intervention. Through their global and national program platforms, networks, and partnerships, the HBB GDA raised awareness about asphyxia-related newborn mortality globally, using a simple educational program and the development of innovative, user-friendly technologies integrated in education programs across the world. It influenced the update of evidence-based global policy recommendations, created awareness about the lack of appropriate indicators for tracking progress and outcomes of resuscitation interventions both at global and country level, and increased the global supply of resuscitation equipment.

Between June 2010 and December 2014, the GDA introduced HBB in 77 countries; most of which were led and coordinated by national governments. This resulted in national plans, policies, and guidelines, inclusion of resuscitation data into existing or newly created registers, training programs and availability of resuscitation devices in facilities. Program reports from several countries indicate a high rate of successful resuscitation, ranging from 79 percent to 89 percent, among babies who did not breathe at birth. An HBB impact study of 80,000 birth over two years in Tanzania reported a significant reduction of 
early newborn mortality (within the first day after birth) by 47 percent and fresh stillbirth by 24 percent. $^{25}$

Neonatal resuscitative care must be integrated within stronger maternal and newborn health systems that provide effective obstetric care. As HBB is aimed at health facilities, in settings where a significant proportion of births occur at home, the reach of HBB is more limited and interim strategies are needed. For example, as countries expand the capacity of facility deliveries, clear articulations are needed of the initial resuscitation steps that can be carried out by community health workers at home births, such as drying, stimulation and airway clearing. One of the most important lessons learned by the GDA partners is that achieving impact requires more than training providers and distributing equipment. The approach to implementation must be tailored to the local context, looks beyond training and provision of equipment to address other system components, and is carefully implemented, monitored and evaluated. Sustaining impact requires government leadership and ownership of the program; institutionalization within national plans and budgets; embedding the new clinical skills and quality improvement skills in pre-service education as well as in-service training; introducing appropriate indicators in national health management information systems; and establishing processes in the health facility on appropriate use of the facility data for self-monitoring and improvement. Equally important is the establishment of partnerships in countries that build on national technical working groups or steering groups and nurturing national champions to demonstrate their leadership in support of the national programs. ${ }^{27}$ 
Figure 1: Adoption curve for global health innovations with reference to Kangaroo Mother Care and antenatal corticosteroids for preterm birth

$\%$ coverage of health intervention in low and middle income countries

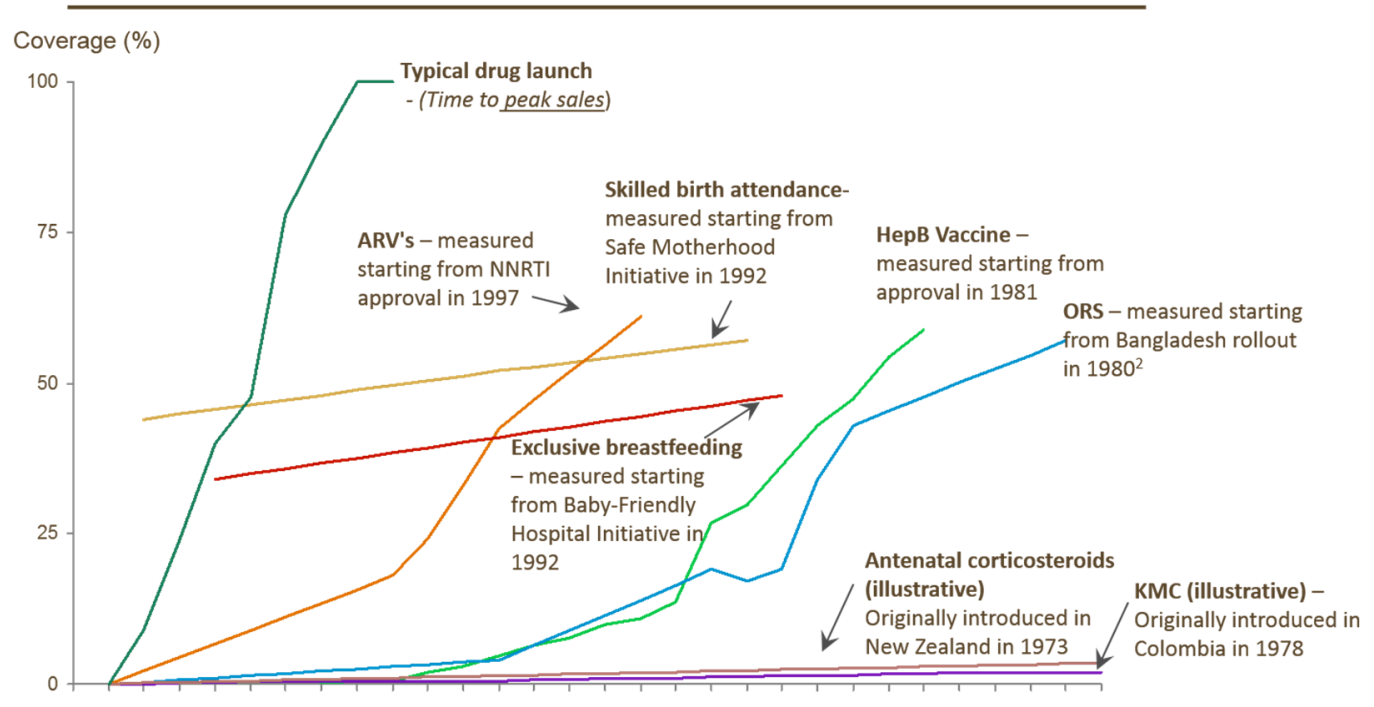

$\begin{array}{lllllllllllllllllllllllllllll}0 & 1 & 2 & 3 & 4 & 5 & 6 & 7 & 8 & 9 & 10 & 11 & 12 & 13 & 14 & 15 & 16 & 17 & 18 & 19 & 20 & 21 & 22 & 23 & 24 & 25 & 26 & 27 & 28\end{array}$

Years from availability of intervention

Source: Darmstadt et al $2014^{4}$ using data from WHO, ${ }^{71}$ UNICEF, ${ }^{72}$ Mahy et al; ${ }^{73}$ Grabowski et al ${ }^{74}$ 
Table 1: Progress towards national newborn health plans in the countries with the highest burden of newborn mortality (deaths and rates)

\begin{tabular}{|c|c|c|c|c|c|c|c|}
\hline Country & $\begin{array}{c}\text { Newborn } \\
\text { deaths } \\
(2013)\end{array}$ & $\begin{array}{c}\text { Newborn } \\
\text { mortality } \\
\text { rate } \\
(2013) \\
\end{array}$ & $\begin{array}{c}\text { National } \\
\text { Newborn } \\
\text { Plan }\end{array}$ & $\begin{array}{c}\text { Newborn } \\
\text { component } \\
\text { strengthened } \\
\text { in RMNCAH } \\
\text { plan }\end{array}$ & $\begin{array}{l}\text { National } \\
\text { plan } \\
\text { costed }\end{array}$ & $\begin{array}{c}\text { Neonatal } \\
\text { mortality } \\
\text { rate target }\end{array}$ & $\begin{array}{c}\text { Stillbirth } \\
\text { rate } \\
\text { target }\end{array}$ \\
\hline Angola & 42,700 & 47 & & & & & \\
\hline Bangladesh & 76,800 & 24 & $x$ & & $x$ & $x$ & $x$ \\
\hline Central African Republic & 6,700 & 43 & & & & & \\
\hline Chad & 22,600 & 40 & & $\mathrm{X}$ & $\mathrm{X}$ & & \\
\hline China & 143,300 & 8 & * & & * & & \\
\hline Democratic Republic of the Congo & 104,700 & 38 & & $x$ & $x$ & $\mathrm{x}$ & \\
\hline Ethiopia & 845,00 & 28 & & * & * & * & \\
\hline Guinea-Bissau & 2,700 & 44 & * & & & & \\
\hline India & 747,600 & 29 & $\mathrm{x}$ & & * & $\mathrm{x}$ & $\mathrm{x}$ \\
\hline Indonesia & 65,900 & 14 & $\mathrm{x}$ & & * & $\mathrm{x}$ & $\mathrm{x}$ \\
\hline Kenya & 39,600 & 26 & $\mathrm{x}$ & & * & $\mathrm{x}$ & \\
\hline Lesotho & 2,600 & 44 & & * & * & $\mathrm{x}$ & \\
\hline Mali & 27,800 & 40 & & $\mathrm{x}$ & & & \\
\hline Nigeria & 261,600 & 37 & * & & & * & \\
\hline Pakistan & 193,800 & 42 & * & & * & $x$ & \\
\hline Sierra Leone & 9,500 & 44 & * & & & & \\
\hline Somalia & 20,800 & 46 & & & & & \\
\hline Zimbabwe & 17,400 & 39 & * & & & $\mathrm{x}$ & \\
\hline \multicolumn{8}{|c|}{$\begin{array}{l}\text { Dark grey rows: } 10 \text { countries with the highest number of newborn deaths } \\
\text { White rows: } 10 \text { countries with the highest newborn mortality rate }\end{array}$} \\
\hline \multicolumn{8}{|c|}{ White rows: 10 countries with the highest newborn mortality rate } \\
\hline
\end{tabular}

Source: WHO, UNICEF. 2015. Every Newborn Progress Report 2015. Geneva: World Health Organization. Data source: UNICEF. 2014. State of the World's Children 2015. Geneva: UNICEF; progress data tracked through specific outreach through UNICEF regional and country offices

Table 2: Prevention and treatment solutions for the main causes of newborn deaths

\begin{tabular}{|c|c|}
\hline Cause of death & Examples of prevention and treatment solutions \\
\hline \multirow[t]{2}{*}{$\begin{array}{l}\text { Complications from } \\
\text { preterm birth }\end{array}$} & $\begin{array}{l}\text { Prevention: antenatal corticosteroid administration to the mother (in } \\
\text { settings that meet criteria) }\end{array}$ \\
\hline & Treatment: Kangaroo Mother Care (KMC) ${ }^{52} 76$ \\
\hline \multirow[t]{2}{*}{ Intrapartum related } & $\begin{array}{l}\text { Prevention: fetal heart rate monitoring and obstetric intervention for } \\
\text { fetal distress; }\end{array}$ \\
\hline & $\begin{array}{l}\text { Treatment: stimulation/resuscitation for live-born babies that don't } \\
\text { breathe spontaneously } 50\end{array}$ \\
\hline \multirow[t]{2}{*}{ Severe newborn infection } & $\begin{array}{l}\text { Prevention: clean delivery and cord care }{ }^{78} \text { hygiene/hand washing, }{ }^{79} \\
\text { breastfeeding, }{ }^{79-82} \text { chlorhexidine cord cleansing (for home births in } \\
\text { settings where NMR is } 30 \text { per } 1,000 \text { live births or more) }{ }^{83,84}\end{array}$ \\
\hline & Treatment: prompt recognition and antibiotics ${ }^{48}$ \\
\hline
\end{tabular}


Table 3: Lessons learned in efforts to support countries to achieve national ENAP milestones

\begin{tabular}{|c|c|}
\hline Activity & Lessons learned \\
\hline Country tracking & $\begin{array}{l}\text { - Revise and simplify country tracking tools to fewer tracer questions and } \\
\text { when possible use indicators that are already monitored by other } \\
\text { mechanisms. } \\
\text { - Improve ways to encourage country colleagues to complete this tool } \\
\text { and find mechanisms for more consistent and systematic follow-up. } \\
\text { - Consider priority/focus countries with high mortality. } \\
\text { - Embed questions into existing surveys, trackers, and monitoring } \\
\text { - } \text { frameworks to reduce the burden on country counterparts. } \\
\text { - Country ownership is critical to sustainability. }\end{array}$ \\
\hline Partner mapping & $\begin{array}{l}\text { - The value of the information increases with the depth of disaggregation } \\
\text { - Ench as by sub-geographic zones or by intervention. } \\
\text { usefulness of the repository as without this, the information becomes } \\
\text { obsolete. } \\
\text { - Triangulation of the information is required to ensure the information is } \\
\text { accurate. } \\
\text { - Investment in strong processes to collect, store, summarise and report } \\
\text { on the data needs to be in line with the ambition for a central } \\
\text { repository for technical support to maternal and newborn care. This } \\
\text { may require a purpose-made survey, and custom-built reports to report } \\
\text { periodically or on demand. }\end{array}$ \\
\hline $\begin{array}{l}\text { Support from multilaterals } \\
\text { and bilaterals }\end{array}$ & $\begin{array}{l}\text { - Working in partnerships. } \\
\text { - Assess context and environment before proposing new interventions, } \\
\text { tools, training modules, health cadres. }\end{array}$ \\
\hline Commitments & $\begin{array}{l}\text { - Commitment generation is a powerful advocacy mechanism. } \\
\text { - Accountability is needed for these commitments to carry weight in } \\
\text { countries and for them to influence implementation. }\end{array}$ \\
\hline $\begin{array}{l}\text { Interventions and } \\
\text { packages }\end{array}$ & $\begin{array}{l}\text { - WHO guidelines have significant influence at national level. } \\
\text { - Context matters for implementation. } \\
\text { - Focus on the highest impact and most feasible approach in context. } \\
\text { - Address missed opportunities for facility births - improve emergency } \\
\text { obstetric care and neonatal resuscitation. } \\
\text { - Implementation of interventions requires investments in health } \\
\text { systems, particularly human resources. }\end{array}$ \\
\hline
\end{tabular}

